\title{
Distinct promoter methylation patterns of LKB1 in the hamartomatous polyps of Peutz-Jeghers syndrome and its potential in gastrointestinal malignancy prediction
}

\author{
Teng Li ${ }^{1}$, Wensheng Lin ${ }^{1,2}$, Yilei Zhao ${ }^{1}$, Jianping Zhu' ${ }^{1}$, Tao Sun ${ }^{3}$ and Li Ren ${ }^{1 *}$
}

\begin{abstract}
Background: Peutz-Jeghers Syndrome (PJS) is known as a rare inherited polyposis due to the malfunction of serine/threonine kinase gene LKB1. However, not all of PJS patients carry LKB1 germline mutation. Previous researches have observed the elevated DNA methylation level in PJS polyps. Nevertheless, the mechanism of such abnormal and its impact on PJS patients remains to be fully described.

Results: The results proved a significant increase on the methylation level of LKB1 promoter in PJS polyps compared with normal colon biopsies through bisulfite PCR followed by Sanger sequencing. Moreover, the methylation pattern in PJS polyps could be further categorized as three different scenarios: hypermethylated, hemimethylated and hypomethylated pattern. Furthermore, immunohistochemistry of DNMT1/3a/3b suggested the up-regulation of DNMT1 and 3a might participate the epigenetic alternation of LKB1 in PJS polyps. Logistic regression suggested hypomethylated $\angle K B 1$ promoter in PJS polyps as a risk factor for gastrointestinal malignancies in PJS patients.

Conclusions: The promoter methylation level of $L K B 1$ gene in PJS polyps is generally elevated compared with normal colon mucosa. Yet not all of PJS polyps carry hypermethylated LKB1 promoter. Hypomethylation in this region has linked to malignant tumors in PJS patients. Given the rarity of PJS, this work together with previous researches, have proved the importance of LKB1 promoter methylation in PJS development and prognosis.
\end{abstract}

Keywords: DNA methylation, Peutz-Jeghers syndrome, Liver kinase B1, Hamartomatous polyp, Colorectal Cancer, Prognosis

\section{Introduction}

Peutz-Jeghers syndrome (PJS) is a rare disease due to the malfunction of LKB1 (STK11) gene [1]. The clinical pathological features to diagnose PJS include: gastrointestinal harmartomatous polyps, mucocutanenous pigmentation and family history [2]. PJS could be lethal for the polyprelated complications, especially intussusceptions, and for

\footnotetext{
* Correspondence: renlifei20000@sina.com

${ }^{1}$ Department of Pathology, Air Force Medical Center, PLA, Beijing, China

Full list of author information is available at the end of the article
}

the substantial risk (up to $86 \%$ of life-time accumulation risk) of adenocarcinoma in the gastrointestinal tract in such patients [3]. Moreover, PJS could harm childhood healthiness, as many PJS patients developed obstruction and intussusception before the age of twenty [4], and those symptoms could be found as early as 4-year old (according to our center's experience). Double balloon pushed enteroscopy (DBE) surveillance have been proved to help PJS patients by detection and removal of polyps and the consequent referral of selected patients for

(c) The Author(s). 2020 Open Access This article is licensed under a Creative Commons Attribution 4.0 International License, which permits use, sharing, adaptation, distribution and reproduction in any medium or format, as long as you give appropriate credit to the original author(s) and the source, provide a link to the Creative Commons licence, and indicate if changes were made. The images or other third party material in this article are included in the article's Creative Commons licence, unless indicated otherwise in a credit line to the material. If material is not included in the article's Creative Commons licence and your intended use is not permitted by statutory regulation or exceeds the permitted use, you will need to obtain permission directly from the copyright holder. To view a copy of this licence, visit http://creativecommons.org/licenses/by/4.0/. The Creative Commons Public Domain Dedication waiver (http://creativecommons.org/publicdomain/zero/1.0/) applies to the data made available in this article, unless otherwise stated in a credit line to the data. 
surgery [5]. The department of gastroenterology of our center is one of the DBE centers in China. Thus, we have collected polyp samples from more than 300 PJS patients.

Although previous researches have proved the majority of PJS patients carry LKB1 exon mutation [69], others suggested $L K B 1$ mutation might not be the only explanation [10]. In 2000, researchers use methylation specific PCR (MSP) method first detected aberrant DNA methylation in PJS patients [11]. Following articles suggested the altered CSX gene DNA methylation patterns in "normal" epithelial crypt of PJS patients [12]. All these data indicated the involvement of DNA methylation in PJS development. However, due to the rarity of PJS and the method limits, the relationship between $L K B 1$ promoter methylation and PJS remains to be described. In this study, we use bisulfite PCR followed by Sanger sequencing to determine the methylation status of $21 \mathrm{CpGs}$ in the promoter of $L K B 1$ gene in 50 PJS polyps and 50 normal colon mucosa. To author's best knowledge, this is the largest dataset for the characterization of DNA methylation in PJS polyps.

\section{Results}

Elevated overall methylation level of $L K B 1$ promoter in PJS polyps

All the PJS polyps and normal mucosa diagnoses were consensus-decisions by three independent pathologists under HE staining (Fig. 1a-d). In order to explore the overall methylation level of $L K B 1$ promoter in PJS polyps and normal mucosa, first we analyzed the promoter region of $L K B 1$ gene and design primers. As shown in Fig. 1e, we selected the core promoter region from the predicted CpG island and designed the bisulfite PCR primer. The PCR product was $259 \mathrm{bp}$, including 21 CpGs from $L K B 1$ core promoter (Fig. 1f). The sequencing results indicated, the overall methylation level for the whole region was significantly higher in PJS group than in normal group (Fig. 1h). However, for each CpG site, the methylation level in both PJS and normal group are similar (Fig. 2g).

Up-regulation of DNMT1 and 3a expression in PJS polyps To explore the mechanism of how $L K B 1$ promoter methylation is elevated, we characterized the expression of three DNMTs, i.e. DNMT1, 3a and 3b, in normal

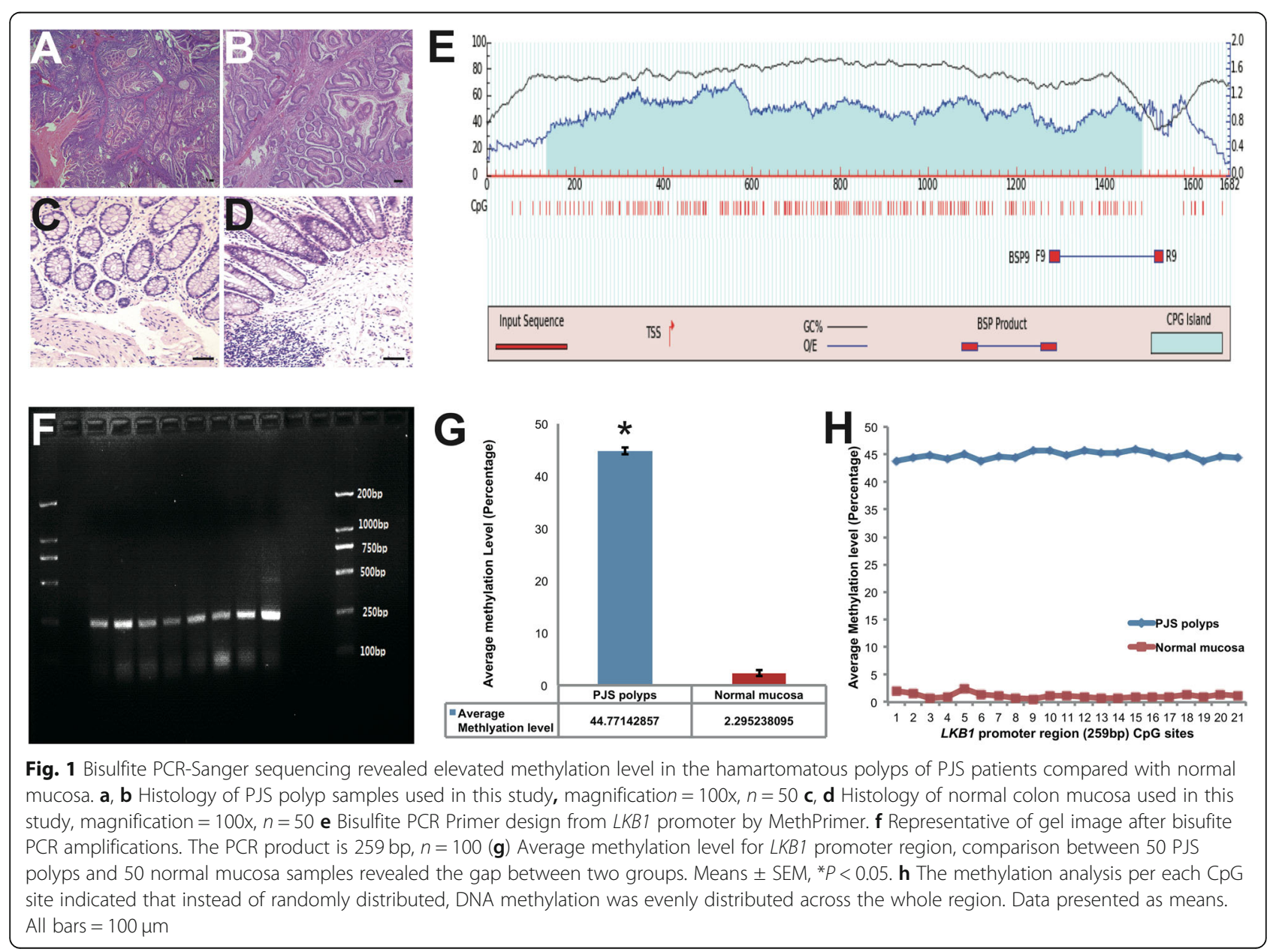




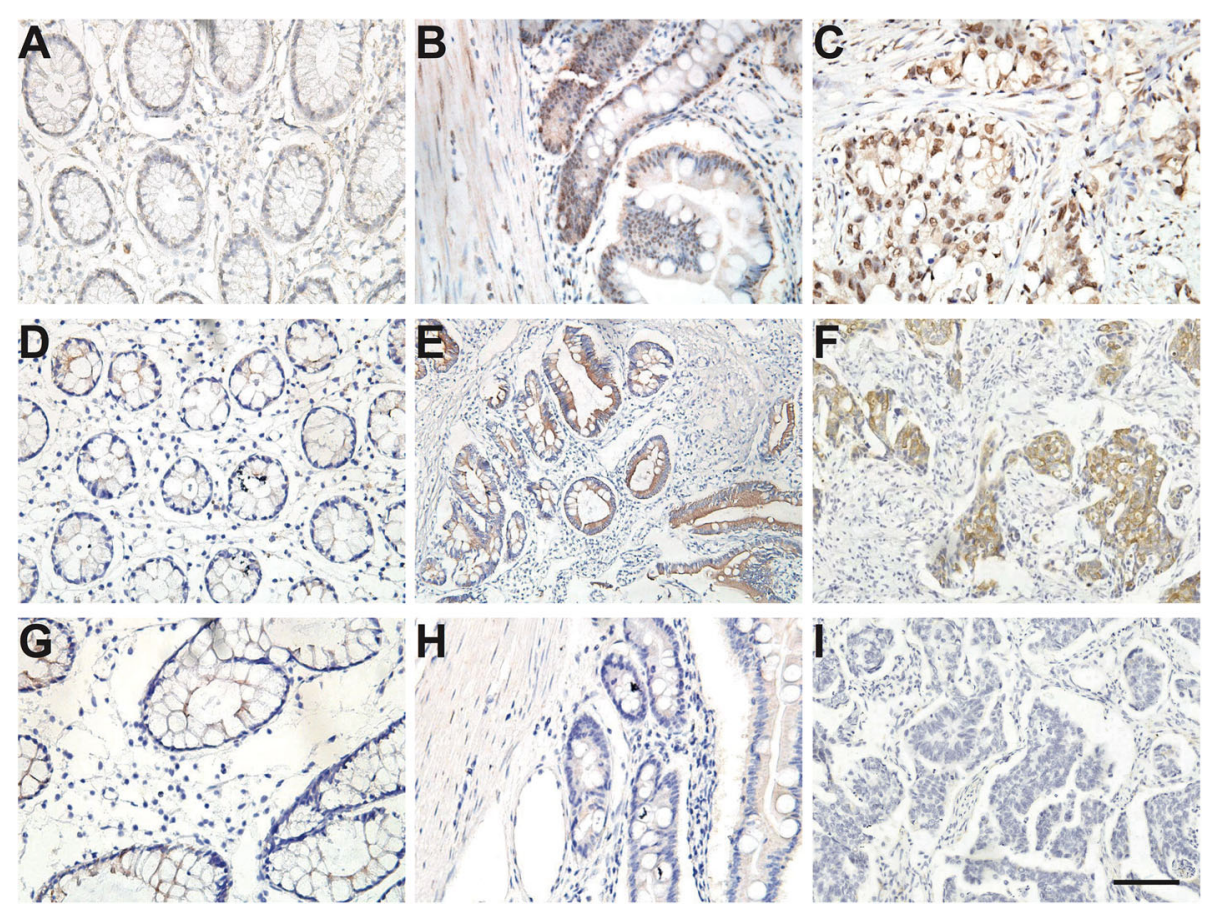

Fig. 2 Characterization of DNMTs' expression in normal colon mucosa, PJS polyps, and colorectal cancer of PJS patients. a-c DNMT1 expression in the above samples. The expression of DNMT1 is increased in PJS polyps and colorectal cancer in PJS patients compared with normal mucosa. $n=15$ (d-f) DNMT3a expression in the above samples. The expression of DNMT3a is increased in PJS polyps and colorectal cancer in PJS patients compared with normal mucosa. $n=15(\mathbf{g}-\mathbf{i})$ DNMT3b immunochemistry results shows negative staining in all the above samples. $n=15 . \operatorname{Bar}=100 \mu \mathrm{m}$

colon mucosa, PJS polyps and colorectal cancer in PJS patients. As shown in Fig. 2a-c, DNMT1 is weakly expressed in normal mucosa, while its expression has elevated in the epithelial cells of PJS polyps and colorectal cancer in PJS patients. Similar to DNMT1, DNMT3a also have strong staining in the epithelial cells of PJS polyps and colorectal cancer in PJS patients compared to the normal samples (Fig. 2d-f). Nevertheless, the expression of DNMT3b remains negative in all three groups (Fig. 2g-i).

\section{Three scenarios for $L K B 1$ promoter methylation in PJS polyps}

In addition to the differential methylation levels, we found three methylation patterns of $L K B 1$ promoter in PJS polyps. We categorized average methylation rate > $75 \%$ as hyper-methylation pattern, between 25 and $75 \%$ as hemi-methylation pattern, and $<25 \%$ as hypomethylation pattern. Among the 50 PJS polyps, 9 were hyper-methylated in $L K B 1$ promoter region, 37 were hemi-methylated and 14 were hypo-methylated (Fig. 3a, b). Intriguingly, the methylation within one read generally follows the all or none rule, i.e. the read is either methylated on all 21 CpGs, or unmethylated for almost all of them. These patterns are usually seen in allelic methylated regions such as imprinting genes or random allelic methylated regions as described in previous researches [13]. Thus, LKB1 promoter methylation could be concluded into three scenarios. For hyper-methylated pattern, both paternal and maternal alleles were methylated. For hemi-methylated pattern, either paternal or maternal allele was methylated. And for hypomethylated pattern, none of those two alleles were methylated (Fig. 3c).

\section{LKB1 promoter hypo-methylation is risk factor of malignancies in PJS patients}

To elucidate the possible impact of methylation level on PJS patients, serial statistical analysis was performed. We tested the average methylation level, age, sex, family history, $L K B 1$ germline mutation, and location between the PJS and control groups. And two factors: average $L K B 1$ methylation level and age are statistically significant.

Further more, PJS groups was divided into two groups by the occurrence of malignancies, and all of the above factors were analyzed by Logistic regression method to seek potential risk factors. The Logistic regression was performed under forward conditional method, and only $L K B 1$ promoter methylation level remains in the equation. The OR value is 0.954 and $P<0.05$ (Table 1 ). Thus, hypomethylated $L K B 1$ promoter might act as a risk factor in the gastrointestinal malignancies of PJS patients. 


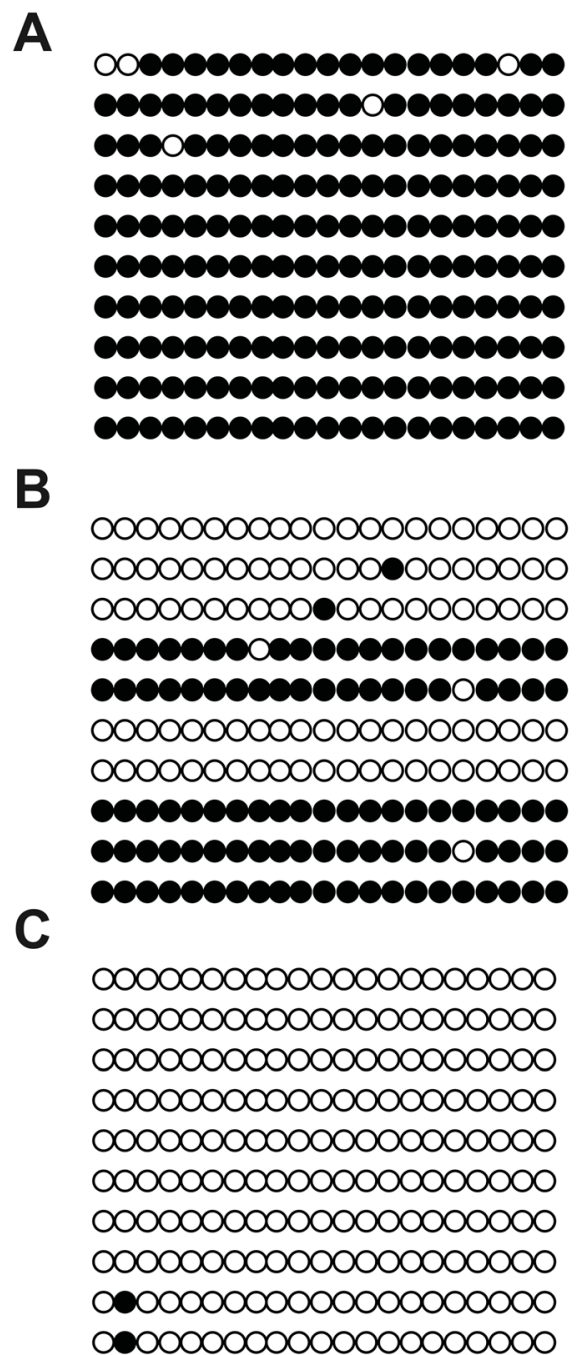

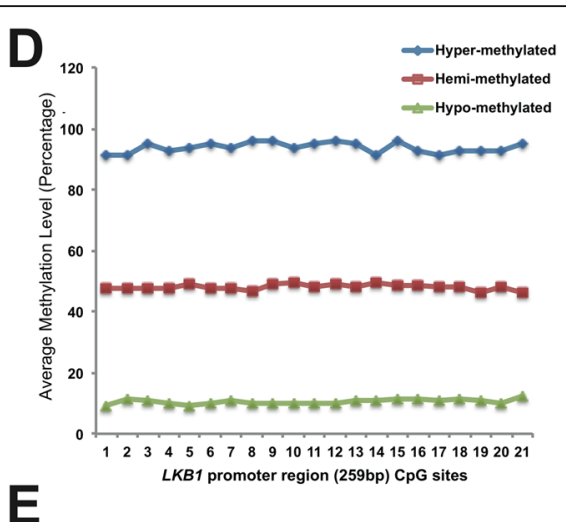

E

Hyper-methylated Pattern

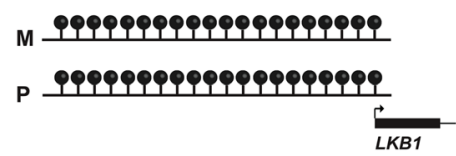

Hemi-methylated Pattern

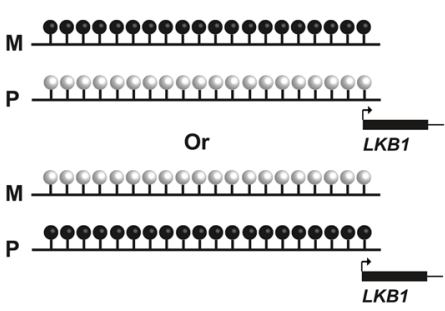

Hypo-methylated Pattern

м sippinipinipininin

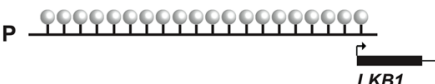

Fig. 3 Distinct promoter methylation patterns of $L K B 1$ in hamartomatous polyps of PJS patients. a-c Representative of three methylation patterns of $L K B 1$ promoter region presented by lollipop graph. a: hyper-methylated pattern; $\mathbf{b}$ : hemi-methylated pattern; $\mathbf{c}$ : hypo-methylated pattern. $\mathbf{d}$ Linear plot for the average methylation level of $L K B 1$ promoter region for all the above patterns. e Diagram of three possible scenarios for different methylation patterns. $M=$ maternal allele, $\mathrm{P}=$ paternal allele

\section{Discussion}

Previous publications have proved the relationship between $L K B 1$ germline mutation and PJS [1, 7-9, 14]. In most of the PJS patients, $L K B 1$ exon mutation could be detected either through PCR based Sanger sequencing [6] or multiplex ligation-dependent probe amplification (MLPA) [15], or even whole exome sequencing [16]. The published mutation rate varies from 66 to $94 \%$ [17]. While in our study, $L K B 1$ germline mutation rate is $72 \%$. These mutations were believed to interfere $L K B 1$ protein expression and/or function and further disturbed the downstream signal such as MAPK, mTOR, etc. [18]. Nevertheless, researchers also found abnormal methylated CpGs in $L K B 1$ promoter region by methylation specific PCR (MSP) method [11]. But since MSP could only detect one or two CpGs at the same time, it is quite difficult to fully evaluate the methylation status of $L K B 1$ promoter, which contains hundreds of CpGs. Other researches indicated that in "normal" crypt of colon from PJS patients, the DNA methylation pattern of cardiac-

Table 1 Evaluation of the relationship between LKB1 promoter methylation level and gastrointestinal malignancies in PJS by Logistic regression

\begin{tabular}{lllllll}
\hline Variant & $\beta$ & S.E & Wald & OR $^{\text {a }}$ & $95 \% \mathrm{Cl}$ & $P$ value \\
\hline LKB1 promoter methylation level & -0.47 & 0.20 & 5.467 & 0.954 & $0.918-0.992$ & 0.038 \\
\hline
\end{tabular}

${ }^{a}$ OR was adjusted by age, gender, family history, LKB1 germline mutation, and polyp locations through forward conditional method 
specific homeobox (CSX) gene is altered and might be related to the protracted clonal evolution in the crypt [12]. All these data suggested abberrant DNA methylation is involved in PJS development.

The overall methylation level in PJS patients is significantly elevated compared to the control group according to the data in this study. Our data together with previous publications has proved the involvement of $L K B 1$ promoter methylation in PJS polyps' development [19]. Furthermore, we discovered distinctive methylation patterns in PJS polyps. Each represents a scenario that might explain how the hamartomatous polyps were developed. Bi-allelic methylation of $L K B 1$ could silence gene expression through prevention by the binding of transcription factors. While, monoallelic methylation of $L K B 1$ could act as secondary "strike", as loss of heterozygosity at $L K B 1$ locus is quite common in PJS patients [20]. However, the role of hypomethylaiton in the development of PJS polys is still not quite clear. And the heterogeneity of $L K B 1$ promoter methylation status suggested it might be a potential factor to further categorizes PJS patients into groups. Thus, we have tested whether LKB1 promoter methylation levels are corelated to the basic characteristics and prognosis of PJS patients. The results indicated that $L K B 1$ promoter hypo-methylation is the risk factor for malignancies among PJS patients. Although the downstream mechanism remains to be elucidated, such data might help to predict the prognosis of PJS and provide us a potential prognostic marker for clinical application.

Currently, PJS patients were recommended to take enteroscopy for every $1-3$ years starting at $8-10$ years $[21,22]$. These examinations have increased the expenditure and reduced the quality of life for PJS patients. LKB1 promoter methylation examination might be a more effective tool to predict the occurrence of malignant gastrointestinal cancer. Nevertheless, more efforts are required to fully evaluate the diagnostic value of $L K B 1$ promoter methylation.

\section{Conclusion}

In this study, the methylation status of $L K B 1$ promoter region in PJS and control group was determined by bisulfite PCR and Sanger sequencing. The comparison between the two groups proved methylation level of PJS polyps is elevated in general. In addition, three distinct methylation patterns in PIS polyps were described. The identification of these patterns enables us to further categorize PJS patients into groups. More importantly, we have discovered lower DNA methylation level in this region has suggested greater chance to suffer from malignant tumors in PJS patients. Altogether, these data might contribute to the prediction of GI malignancis in
PJS patients, and add an alternative tool with the current surveillance strategy.

\section{Material and methods}

The purpose of this study was to compare PJS polyp and normal mucosa from their DNMTs expression and $L K B 1$ promoter methylation status, aiming at exploring the role of DNMTs in $L K B 1$ promoter methylation.

\section{Patients and sample collection}

The PJS patients included in this study comprises $50 \mathrm{pa}-$ tients with DBE polypectomy from 2015 to 2018 in our hospital (Table 1). For each case, PJS is diagnosed by WHO criteria (any one of below): $\geq 3$ hamartomatous polyps; or $\geq 1$ hamartomatous polyps if family history of Peutz-Jeghers Syndrome (PJS); or prominent mucocutaneous melanosis if family history of PJS; or prominent mucocutaneous melanosis and $\geq 1$ hamartomatous polyp. Only FFPE tissues from patients met the above criteria were selected for DNA extraction. As for control samples, colonoscopy biopsies were taken from routine physical examination of 50 healthy adults. The general information for patients enrolled is detailed in Table 2.

Table 2 General characteristic of PJS and control groups used in this study

\begin{tabular}{lll}
\hline Characteristics & PJS cases $(N=50)^{a}$ & Control $(N=50)^{a}$ \\
\hline Age (years) & $16(32 \%)$ & $2(4 \%)$ \\
$\leq 20$ & $15(30 \%)$ & $8(16 \%)$ \\
$21-30$ & $18(36 \%)$ & $22(44 \%)$ \\
$31-50$ & $1(2 \%)$ & $18(36 \%)$ \\
$>50$ & & $15(30 \%)$ \\
Gender & $20(40 \%)$ & $35(70 \%)$ \\
Female & $30(60 \%)$ & 0 \\
Male & & $6(12 \%)$ \\
Polyp/biopsy location & & $44(88 \%)$ \\
Stomach & $2(4 \%)$ & \\
Intestine & $32(64 \%)$ & 0 \\
Colon & $16(32 \%)$ & $50(100 \%)$ \\
Gl Malignancies & $8(16 \%)$ & 0 \\
Yes & $42(84 \%)$ & $50(100 \%)$ \\
No & $27(54 \%)$ & \\
Family History & $23(46 \%)$ & \\
Yes & $10(27.8 \%)$ & \\
No & & \\
LKB1 germline mutation & \\
Yes & & \\
No & & \\
\hline
\end{tabular}

${ }^{a}$ Data were presented in number (percentage). Total number may not be equal to the total of cases or controls due to missing or unknown data 


\section{DNA extraction and bisulfite treatment}

Genomic DNA was extracted using FFPE Tissue Genomic DNA Kit (Hooseen bio) following manufacturer's instructions. Briefly, the FFPE tissue was cut into slices, and incubated with GA buffer in $90^{\circ} \mathrm{C}$ water bath for 30 min. Centrifuge at $12000 \mathrm{rpm}$ for $2 \mathrm{~min}$, discard the paraffin layer and transfer the residue to a new tube. Add $25 \mu \mathrm{l}$ proteinase $\mathrm{K}$ and incubated in $55^{\circ} \mathrm{C}$ water bath until the tissue is fully dissolved. Transfer the supernatant and mix with GB buffer, incubate in $70^{\circ} \mathrm{C}$ for 10 min. Add $250 \mu \mathrm{l}$ ethanol, vortex and transfer to DNA conjugation column. Centrifuge at $12000 \mathrm{rpm}$ for $30 \mathrm{~s}$. Discard the residue and wash with GD buffer twice and elute with $40 \mu \mathrm{lEB}$ buffer. DNA was stored at $-20^{\circ} \mathrm{C}$. Meanwhile, genomic DNA of these PJS patient was also extracted from whole blood cells as previously reported.

Bisulfite treatment was performed through EZ DNA Methylation-Lightning Kit (Zymo research). Briefly, $1 \mu \mathrm{g}$ of genomic DNA was added to $130 \mu$ l Lightning conversion reagent, incubated at $98{ }^{\circ} \mathrm{C}$ for $8 \mathrm{~min}$ and then $54{ }^{\circ} \mathrm{C}$ for $60 \mathrm{~min}$. The mixture was then loaded to column with $600 \mu \mathrm{l}$ M-binding buffer. Centrifuge at $12000 \mathrm{rpm}$, and wash with $100 \mu \mathrm{l} \mathrm{M}$-wash buffer. After $20 \mathrm{~min}$ incubation with $200 \mu \mathrm{L}$-Desulphonation buffer, centrifuge at $12000 \mathrm{rpm}$ and wash the column twice with $200 \mu \mathrm{lM}$ wash buffer. Discard all residues and elute with $10 \mu \mathrm{lEB}$ buffer. Bisulfite treated DNA was stored at $-20^{\circ} \mathrm{C}$.

\section{LKB1 germline mutation detection}

PCR primer of all $L K B 1$ exons and reaction set up was according to previous published literature [23]. The PCR product was loaded to $2 \%$ agarose gel and purified by TIANgel Mini Purification Kit (TIAGEN), and then sent for Sanger sequencing (Sangon Biotech). The result was aligned with reference genomic sequence of $L K B 1$ (GRCh37.p13) and all SNPs were excluded through crosscheck with NCBI SNP database.

\section{Immunohistochemistry of DNMT1, 3a and 3b}

The FFPE tissues were cut with $4 \mu \mathrm{m}$ slides, and emerged in xylene to remove the paraffin and followed by graded ethanol. Heat-induced epitope retrieval was conducted in EDTA solution ( $\mathrm{pH}$ 9.0). Endogenous peroxidase was blocked by $3 \% \mathrm{H}_{2} \mathrm{O}_{2}$ for $10 \mathrm{~min}$. Rinse the slides with $\mathrm{PBS}$ and incubate with primary antibody (DNMT1: CatNo. 39,204, mouse monoclonal, Active Motif, dilution 1:200; DNMT3a: CatNo. ab13888, mouse monoclonal, Abcam, dilution 1:200; DNMT3b: CatNo. ab2851, rabbit polyclonal, Abcam, dilution 1:200) for 45 min. After PBS rinse, secondary antibody (REAL EnVision Detection System, Rabbit/Mouse, CatNo. K5007, DAKO) was incubated for $20 \mathrm{~min}$ and rinse again with PBS. Positive staining was developed by DAB for 3-5 min and slides were emerged in graded ethanol and xylene eventually sealed with cover slides.

\section{LKB1 promoter methylation analysis}

Bisulfite treated DNA and KAPA HiFi HotStart Uracil + ReadyMix PCR Kit (KAPA biosystems) was used to set up the system for amplification. The bisulfite PCR primers for $L K B 1$ promoter were designed on MethPrimer website (Fig. 1e) [24]. The primer sequences are listed as follow: Forward 5' - GAG GAT GAT TTA GTA TTG AAA AGT-3'; Reverse 5' - AAC AAC AAA AAC CCC AAA AA-3', product size: $259 \mathrm{bp}$ (containing $21 \mathrm{CpG}$ sites). The reaction was performed under $95^{\circ} \mathrm{C}$ for $5 \mathrm{~min}$, followed with 39 cycles of $98^{\circ} \mathrm{C}$ for $20 \mathrm{~s}, 59^{\circ} \mathrm{C}$ for $15 \mathrm{~s}$, and $72{ }^{\circ} \mathrm{C}$ for $1 \mathrm{~min}$; and then $72^{\circ} \mathrm{C}$ for $10 \mathrm{~min}$. The product was uploaded to $1.5 \%$ agarose gel and the purification was done by TIANgel Mini Purification Kit (TIANGEN). The purified product was ligated to pGMSimple-T Fast Vector (TIANGEN) by T4 DNA ligase (NEB). The ligated vector was transfected into $\mathrm{DH} 5 \alpha$ competent cells. LB agar plate was used for monoclonal selection. Sanger sequencing was sent to Sangon Biotech. Each sample was required at least 10x coverage. Sequences was aligned to reference $L K B 1$ promoter sequence, and visualized by BiQ analyzer [25].

\section{Statistical analysis}

The SPSS 22.0 software was used for statistical analysis. The comparison between PJS and control group on $L K B 1$ methylation levels, age, sex, family history, $L K B 1$ germline mutation, and polyp location was performed by Kruskal Wallis Test. Odds ratio (OR) was calculated by logistic regression (forward conditional method) to evaluate the association between methylation levels of $L K B 1$ with the risk for gastrointestinal malignancies in PJS patients, adjusting for age, sex, polyp location, family history, and $L K B 1$ germline mutation. $P<0.05$ is considered statistically significant.

\section{Supplementary information}

Supplementary information accompanies this paper at https://doi.org/10. 1186/s13023-020-01502-9.

\section{Additional file 1.}

\section{Abbreviations}

LKB1: Liver Kinase B1; PJS: Peutz-Jeghers Syndrome; DNA: Deoxyribonucleic Acid; DNMT: DNA Methyltransferase; DBE: Double balloon pushed enteroscopy; PCR: Polymerase Chain Reaction; WHO: World Health Organization; FFPE: Formalin-Fixed and Paraffin-Embedded;

Gl: Gastrointestinal; NCBI: National Center for Biotechnology Information; SNP: Single nucleotide polymorphism; EDTA: Ethylene Diamine Tetraacetic Acid; PBS: Phosphate Buffered Saline; DAB: Diaminobenzidine; LB: Lysogeny broth; OR: Odds ratio; HE: Hematoxylin eosin; SEM: Standard error for mean; S.E: Standard error; Cl: Confidence interval; MLPA: Multiplex ligationdependent probe amplification; MSP: Methylation specific polymerase chain reaction; CSX: Cardiac-specific homeobox 


\section{Acknowledgements}

Clinical perspective from Dr. Shoubin Ning from the Department of Gastroenterology is gratefully acknowledged. Technical assistance from Yarui Cao and Meng Li is also gratefully acknowledged. All participants contributing to the original study subjects recruit are acknowledged.

\section{Authors' contributions}

Teng Li and Li Ren conceived and designed the study. Teng Li performed the experiments, conducted data analyses, interpreted the data, and drafted the manuscript. Wensheng Lin and Yilei Zhao helped with the experiments. Jianping Zhu helped provide reagents, materials, and experimental infrastructure. Tao Sun contributed to $L K B 1$ germline mutation information. All authors read and approved the definitive version of the manuscript.

\section{Funding}

This work was supported by the Beijing Nova Program, Ministry of Science and Technology, Beijing, China (Grant No. Z181100006218065), and grant from Junior Scientists Fund (16QNP025) to Teng Li.

\section{Availability of data and materials}

The major data sets supporting the results of this article are included within the article and its additional files.

\section{Ethics approval and consent to participate}

The study protocol was approved by the Institutional Review Board of Air Force Medical Center.

\section{Consent for publication}

Written informed consent for publication was obtained from all participating PJS patients and healthy adults.

\section{Competing interests}

The authors declare that they have no competing interests.

\section{Author details}

'Department of Pathology, Air Force Medical Center, PLA, Beijing, China. ${ }^{2}$ Department of Pathology, Huizhou Third People's Hospital, Guangzhou Medical University, Huizhou, China. ${ }^{3}$ Department of Gastroenterology, Air Force Medical Center, PLA, Beijing, China.

Received: 19 December 2019 Accepted: 9 August 2020

Published online: 15 August 2020

\section{References}

1. Hemminki A, Markie D, Tomlinson I, Avizienyte E, Roth S, Loukola A, et al. A serine/threonine kinase gene defective in Peutz-Jeghers syndrome. Nature. 1998;391(6663):184-7.

2. Shussman N, Wexner SD. Colorectal polyps and polyposis syndromes. Gastroenterol Rep (Oxf). 2014;2(1):1-15.

3. van Lier MG, Westerman AM, Wagner A, Looman CW, Wilson JH, de Rooij FW, et al. High cancer risk and increased mortality in patients with PeutzJeghers syndrome. Gut. 2011;60(2):141-7.

4. Beggs AD, Latchford AR, Vasen HF, Moslein G, Alonso A, Aretz S, et al. Peutz-Jeghers syndrome: a systematic review and recommendations for management. Gut. 2010;59(7):975-86.

5. van Lier MG, Wagner A, Mathus-Vliegen EM, Kuipers EJ, Steyerberg EW, van Leerdam ME. High cancer risk in Peutz-Jeghers syndrome: a systematic review and surveillance recommendations. Am J Gastroenterol. 2010;105(6): 1258-64 author reply 65

6. Lipsa A, Kowtal P, Sarin R. Novel germline STK11 variants and breast cancer phenotype identified in an Indian cohort of Peutz-Jeghers syndrome. Hum Mol Genet. 2019;28(11):1885-93.

7. Aretz S, Stienen D, Uhlhaas S, Loff S, Back W, Pagenstecher C, et al. High proportion of large genomic STK11 deletions in Peutz-Jeghers syndrome. Hum Mutat. 2005;26(6):513-9.

8. Papp J, Kovacs ME, Solyom S, Kasler M, Borresen-Dale AL, Olah E. High prevalence of germline STK11 mutations in Hungarian Peutz-Jeghers syndrome patients. BMC Med Genet. 2010;11:169.

9. Liu L, Du X, Nie J. A novel de novo mutation in LKB1 gene in a Chinese Peutz Jeghers syndrome patient significantly diminished p53 activity. Clin Res Hepatol Gastroenterol. 2011;35(3):221-6.
10. Duan FX, Gu GL, Yang HR, Yu PF, Zhang Z. Must Peutz-Jeghers syndrome patients have the LKB1/STK11 gene mutation? A case report and review of the literature. World J Clin Cases. 2018;6(8):224-32.

11. Esteller M, Avizienyte E, Corn PG, Lothe RA, Baylin SB, Aaltonen LA, et al. Epigenetic inactivation of LKB1 in primary tumors associated with the Peutz-Jeghers syndrome. Oncogene. 2000;19(1):164-8.

12. Langeveld D, Jansen $M$, de Boer DV, van Sprundel M, Brosens LA, Morsink $\mathrm{FH}$, et al. Aberrant intestinal stem cell lineage dynamics in Peutz-Jeghers syndrome and familial adenomatous polyposis consistent with protracted clonal evolution in the crypt. Gut. 2012;61(6):839-46.

13. Martos SN, Li T, Ramos RB, Lou D, Dai H, Xu JC, et al. Two approaches reveal a new paradigm of 'switchable or genetics-influenced allele-specific DNA methylation' with potential in human disease. Cell Discov. 2017:3:17038.

14. Jenne DE, Reimann H, Nezu J, Friedel W, Loff S, Jeschke R, et al. PeutzJeghers syndrome is caused by mutations in a novel serine threonine kinase. Nat Genet. 1998;18(1):38-43.

15. Tan H, Mei L, Huang $Y$, Yang $P$, Li H, Peng $Y$, et al. Three novel mutations of STK11 gene in Chinese patients with Peutz-Jeghers syndrome. BMC Med Genet. 2016;17(1):77

16. Wang HH, Xie NN, Li QY, Hu YQ, Ren JL, Guleng B. Exome sequencing revealed novel germline mutations in Chinese Peutz-Jeghers syndrome patients. Dig Dis Sci. 2014;59(1):64-71.

17. Zbuk KM, Eng C. Hamartomatous polyposis syndromes. Nat Clin Pract Gastroenterol Hepatol. 2007;4(9):492-502.

18. Shackelford DB, Shaw RJ. The LKB1-AMPK pathway: metabolism and growth control in tumour suppression. Nat Rev Cancer. 2009:9(8):563-75.

19. Trojan J, Brieger A, Raedle J, Esteller M, Zeuzem S. 5'-CpG island methylation of the LKB1/STK11 promoter and allelic loss at chromosome 19p13.3 in sporadic colorectal cancer. Gut. 2000;47(2):272-6.

20. Mehenni H, Resta N, Guanti G, Mota-Vieira L, Lerner A, Peyman M, et al. Molecular and clinical characteristics in 46 families affected with PeutzJeghers syndrome. Dig Dis Sci. 2007;52(8):1924-33..

21. Kanth P, Grimmett J, Champine M, Burt R, Samadder NJ. Hereditary colorectal polyposis and Cancer syndromes: a primer on diagnosis and management. Am J Gastroenterol. 2017;112(10):1509-25.

22. Latchford A, Cohen S, Auth M, Scaillon M, Viala J, Daniels R, et al. Management of Peutz-Jeghers Syndrome in children and adolescents: a position paper from the ESPGHAN polyposis working group. J Pediatr Gastroenterol Nutr. 2019;68(3):442-52.

23. Mao X, Zhang Y, Wang H, Mao G, Ning S. Mutations of the STK11 and FHIT genes among patients with Peutz-Jeghers syndrome. Zhonghua Yi Xue Yi Chuan Xue Za Zhi. 2016;33(2):186-90.

24. Li LC, Dahiya R. MethPrimer: designing primers for methylation PCRs. Bioinformatics. 2002;18(11):1427-31.

25. Bock C, Reither S, Mikeska T, Paulsen M, Walter J, Lengauer T. BiQ analyzer: visualization and quality control for DNA methylation data from bisulfite sequencing. Bioinformatics. 2005;21(21):4067-8.

\section{Publisher's Note}

Springer Nature remains neutral with regard to jurisdictional claims in published maps and institutional affiliations.
Ready to submit your research? Choose BMC and benefit from:

- fast, convenient online submission

- thorough peer review by experienced researchers in your field

- rapid publication on acceptance

- support for research data, including large and complex data types

- gold Open Access which fosters wider collaboration and increased citations

- maximum visibility for your research: over $100 \mathrm{M}$ website views per year

At $\mathrm{BMC}$, research is always in progress.

Learn more biomedcentral.com/submissions 